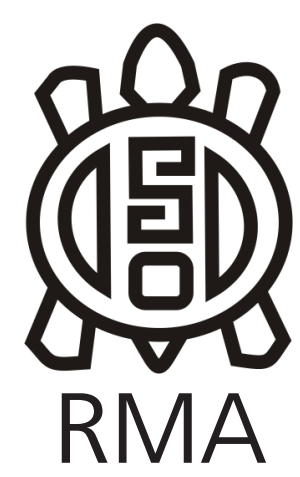

Dossier

\title{
Primeros acercamientos a los estudios líticos desde diversas tendencias teórico metodológicas
}

\author{
First approaches to lithic studies from various theoretical and \\ methodological trends
}

Camila de Fátima Brizuela*

* Instituto de Antropología de Córdoba (IDACOR-CONICET), Museo de Antropología, Facultad de Filosofía y Humanidades, Universidad Nacional de Córdoba.

E-mail: cami.f.brizuela@gmail.com

Dando lugar a la posibilidad de expresión a futurxs arqueólogxs en pleno proceso de formación, se decidió apostar a la generación de un espacio de intercambio de resultados y avances de investigación alcanzados. Se constituyó así una Mesa de Estudiantes en el $1^{\circ}$ Congreso Argentino de Estudios Líticos en Arqueología ( $\left.1^{\circ} \mathrm{CAELA}\right)$ realizado en septiembre de 2018 , siendo una excelente oportunidad para dialogar y reflexionar sobre los diversos casos referidos al estudio del material lítico desde una vasta pluralidad de marcos teóricos y metodológicos, como así también temporales y espaciales.

Contamos en primer lugar con el trabajo de Ixs Licenciadxs en Antropología de la Universidad Nacional de Córdoba Bernarda Conte (entonces estudiante) y Andrés Robledo, titulado: "Aplicación de tecnologías 3D en sitios arqueológicos del valle de Ongamira, Córdoba, Argentina. Fotogrametría en excavaciones y morteros arqueológicos". Dicho trabajo constituye un aporte en la aplicación de nuevas tecnologías digitales dentro de los estudios arqueológicos. Para ello, a partir de tareas de relevamiento y prospección en el valle de Ongamira, generaron modelos virtuales de morteros localizados en distintos lugares y sobre excavaciones estratigráficas en sitios al aire libre y aleros. Buscando contribuir al desarrollo de técnicas digitales en el relevamiento y posterior estudio de lugares con evidencias de actividades humanas en el pasado. Se utilizó la técnica de fotogrametría, se llevó a cabo el registro de 3 aleros rocosos con evidencias de ocupación, 8 pozos de excavaciones y 5 morteros, de los cuales 4 eran móviles y uno era en la roca base. Dicha técnica requiere la toma fotos de forma sistemática en diferentes ángulos. Luego de fotografiar la totalidad del objeto o el rasgo, se realizó un modelo digital en base a los programas VisualSFM y Meshlab. Todos los modelos fueron publicados en el repositorio digital Suquía (www. suquia.ffyh.unc.edu.ar) en el marco del Programa de Arqueología Digital, con el fin de aportar a la conservación y divulgación del registro arqueológico.

En segundo lugar, presentamos la contribución de la estudiante de la Escuela de Arqueología de la Universidad
Nacional de Catamarca, Mariana Ávila Navas, con su trabajo titulado: "Primeros avances en la caracterización de la tecnología lítica en el Holoceno final del norte de San Luis". La autora aborda el análisis técnico morfológico de una muestra lítica obtenida en el Chimborazo 1, ubicado en un sector semi-árido del norte de la provincia de San Luis, Argentina. El mismo se trata de un sitio a cielo abierto, donde se visualizan hornillos y abundante material lítico disperso en antiguas terrazas aluviales del arroyo Los Hornos. Actualmente se encuentra sometido a un proceso de erosión que moviliza los materiales superficiales y destruye hornillos gradualmente. En ese marco, las recolecciones superficiales permitieron recuperar elementos para analizar desde un marco de la Organización de la Tecnología. El mismo estuvo enfocado en brindar un primer acercamiento sobre la gestión tecnológica que se estaba desarrollando en el sitio, como así también las instancias, técnicas de talla y materias primas utilizadas. Este primer análisis indica que se llevaban a cabo un proceso de talla que involucraría hasta las etapas intermedias, con la presencia tanto de desechos, núcleos como instrumentos realizados en diferentes materias primas (cuarcita, cuarzo y calcedonia). Dichos instrumentos estarían relacionados con posibles tareas de corte y raspado.

Finalmente contamos con el trabajo de la Licenciada en Antropología de la Universidad Nacional de Córdoba Camila Brizuela (entonces estudiante), titulado: "Un abordaje del diseño, los gestos técnicos y las huellas de uso en instrumentos líticos experimentales (gubias, escoplos y cinceles), desde una aproximación funcional". Mediante un programa experimental y la metodología de análisis funcional de base microscópica como así también el estudio tipológico, el trabajo buscó entender los aspectos sociales que permitieran reconocer y describir habitus o modos de hacer, focalizando en el estudio del diseño, los gestos técnicos y las huellas de uso que quedan registradas en las aristas activas y planos activos del instrumental lítico. Pretendiendo así, contribuir con la discusión de la relación entre diseño/forma y función de los instrumentos 
líticos; centrando el interés específicamente en tres grupos tipológicos definidos por Hocsman y Aschero (2015) como gubias, escoplos y cinceles. Puesto que los autores discuten aspectos vinculados con las "variables morfológico-funcionales", las "funciones primarias", su vinculación con "modos de acción" específicos y las "características de performance"; la autora plantea una caracterización y contrastación entre las huellas/gestos de uso y la variabilidad morfológica de estos grupos, buscando analizar las variables micro-morfológicas que los caracterizan y evaluar posibles similitudes y/o diferencias en sus contextos de uso y en las evidencias microscópicas de las áreas activas de estos instrumentos.

La enriquecedora participación de Ixs estudiantes brindó una oportunidad de encuentro novedosa y propicia para la discusión científica de innumerables problemáticas arqueológicas con respecto a los conjuntos líticos. Los trabajos presentados en este Dossier constituyen solo una parte de lo expuesto en dicho Congreso. 